\title{
The immorality of computer games: Defending the endorsement view against Young's objections
}

\author{
Sebastian Ostritsch ${ }^{1} \cdot$ Samuel Ulbricht ${ }^{1}$
}

Published online: 14 August 2020

(c) The Author(s) 2020

\begin{abstract}
Garry Young has made three objections against Sebastian Ostritsch's endorsement view on the immorality of computer games. In this paper, we want to defend the endorsement view against all three of them.
\end{abstract}

Keywords Ethics $\cdot$ Computer games $\cdot$ Video games $\cdot$ Endorsement view $\cdot$ Amoralist challenge

\section{Introduction}

Garry Young has made three objections against Sebastian Ostritsch's endorsement view on the immorality of computer games. According to the endorsement view, computer games ${ }^{1}$ are immoral in case they endorse an immoral worldview. Endorsement is different from mere representation insofar as it suggests certain attitudes, beliefs or values with respect to reality. According to the endorsement view, the player may play any computer game without any moral blame. However, he has a moral obligation to detect, reflect on and reject any immoral real-world attitudes, beliefs and values that an immoral game might endorse (Ostritsch 2017, pp. 122-127).

Ostritsch develops the endorsement view as an answer to the amoralist challenge. The latter consists in the observation that games constitute an amoral reality, i.e. a reality of their own within which the moral norms of the real world are not in effect (Ostritsch 2017, p. 117 f.). Faced with moral criticism for playing violent or otherwise seemingly immoral games, gamer's will often reply by stating that "It's just a game". This statement captures the very spirit of the amoralist position. In his original paper, Ostritsch first defends the amoralist as far as virtual acts are concerned: Neither the utilitarian nor the Kantian nor the virtue ethicist can

Sebastian Ostritsch

sebastian.ostritsch@philo.uni-stuttgart.de

Samuel Ulbricht

Samuel.Ulbricht@posteo.de

1 Department of Philosophy, University of Stuttgart, Seidenstraße 36, 70174 Stuttgart, Germany show why carrying out certain virtual acts like virtual murder or virtual pedophilia is inherently immoral (Ostritsch 2017, pp. 118-120). Ostritsch then goes on to argue that the moral wrongness is to be located not in the virtual actions of the player but in the game itself. The moral wrongness in turn depends not on the representations shown on the screen but on a potential endorsement of an immoral worldview (Ostritsch 2017, pp. 122-125).

Young's first objection targets an argument made by Ostritsch against the expressivist view that playing certain games (like the notorious rape game RapeLay) is wrong because it is expressive of an immoral character (Patridge 2011, p. 305 f.). Ostritsch argues against this view by pointing out that enjoying a computer game of questionable moral content like RapeLay (Illusion 2006) is only immoral if the enjoyment is of a "strong" and not of a "weak" kind (Ostritsch 2017 , p. 120 f.). And the mere fact that someone is playing a computer game does not tell us which type of enjoyment is involved. Young, however, believes that the notion of strong enjoyment is "too crude" (Young 2017a, p. 212).

With his second objection, Young attacks the claim that games themselves can be immoral. According to Young, the fact that people can rationally disagree about the morality or immorality of a game implies a constructivist meta-ethical theory he calls "constructive ecumenical expressivism" or short "CEE" (Young 2017a, p. 215). CEE, in turn, is incompatible with judgments made by the endorsement view about the objective morality or immorality of a game.

Thirdly, Young disagrees that players can be morally obliged to take a certain attitude towards games of a

\footnotetext{
${ }^{1}$ In the following, "computer game", "video game" and "game" are used interchangeably.
} 
questionable content. Instead of being subject to a moral evaluation, the player's reaction to a game is supposed to be one of good or bad taste according to Young. He argues for this view by drawing on the category of suberogatory actions, i.e. actions that ought not be carried out but that are not immoral (Young 2017a, p. 217 f.).

In this paper, we want to defend the endorsement view against all three objections. We argue that the first objection is not an objection at all. Rather, it offers the basis for a more fine grained analysis of different kinds of enjoyment, an analysis which helps to make the point of the original argument against expressivism even clearer. ${ }^{2}$ We go on to argue that the second and the third objection are not pertinent for meta-ethical reasons.

\section{Young's first objection: different types of enjoyment}

Young's first objection targets an argument that Ostritsch makes against the expressivist. According to the expressivist, we are justified in believing that someone who plays a game like RapeLay is doing something immoral not because of any consequences but because his actions are expressive of an immoral character (Patridge 2011, p. 305 f.). According to Ostritsch, however, in the case envisioned by the expressivist, a player is only doing something morally objectionable if he plays a game that has representations of morally objectionable actions and he enjoys those representations in a strong sense of 'to enjoy'. The player is not doing anything wrong, if he plays a game that has representations of morally objectionable actions and he enjoys these representations only in a weak sense of 'to enjoy' (Ostritsch 2017, p. 121). Therefore, the expressivist argument does not go through without further qualifying the type of enjoyment involved in playing the game. The difference between 'weak' and 'strong' enjoyment can be summed up as follows: Weak enjoyment is enjoyment in the general sense of being interested or captivated by something. Strong enjoyment, on the other hand, is affirmative enjoyment in the sense of having fun.

Young believes that Ostritsch's notion of strong enjoyment is "too crude" (Young 2017a, p. 209, 211, 212) because, according to him, there are several ways to enjoy video games in a strong sense and only some of them are morally questionable when related to an immoral game. Young states that Ostritsch's inaccuracy leads to the

\footnotetext{
$\overline{2}$ It should be pointed out that Young himself does not object to the goal of proffering "a rebuttal of the amoralist's challenge" (Young 2017a, p. 218). However, he does object to "the manner in which he [i.e. Ostritsch] defends his position" (Young 2017a, p. 209). We argue that Young's first objection does not point to an error in Ostritsch's argument, however it can be used to strengthen the latter further. In this sense, we argue, Young's first objection is not really an objection.
}

following contradiction: On the one hand, the immorality of enjoying a morally objectionable game $\mathrm{x}$ "is dependent on whether x prompt us to endorse immorality" (Young 2017a, p. 212). On the other hand, the immorality of enjoying $x$ is not dependent on such an endorsement. Young claims that to avoid the contradiction one must distinguish between different types of wrongdoing related to video games, "so that it is true that in certain cases the dependency relation exists and in certain cases it does not" (Young 2017a, p. 212). To achieve this goal, which Ostritsch allegedly fails to accomplish, Young draws a distinction between two different types of strong enjoyment.

In the following section we will discuss Young's suggested improvement to Ostritsch's argument. In the process it will become clear that Ostritsch's argument is not threatened by the alleged contradiction.

(i) As a first example, Young discusses " $\mathrm{M}_{\text {(enjoyment) }}$ which he defines as follows:

$M_{\text {(enjoyment): }}$ S engages in the virtual act because $S$ anticipates that it will be fun/thrilling. S anticipates that it will be fun/thrilling because the virtual act represents something that is taboo. In short, $\mathrm{S}$ desires to engage in the virtual enactment because the symbolic violation of the real-world taboo (i.e., what the virtual enactment represents), in virtue of being the enactment of a taboo, is something S anticipates deriving enjoyment from. (Young 2017a, p. 212)

This means that someone who is motivated to play the rape game RapeLay because of $\mathrm{M}_{\text {(enjoyment) }}$ is enjoying the game in a strong sense, and yet, it is not clear that his motivation is morally reproachable. On the contrary, one might even argue that it can be beneficial to the development of one's moral character to experience the breaking of moral taboos within the safe confines of a virtual world. ${ }^{3}$ After all, the subject of $\mathrm{M}_{\text {(enjoyment) }}$ recognizes the immoral content and interprets it correctly as taboo. Therefore, he exhibits at least some degree of critical moral reflection. If someone identifies a taboo as taboo, he knows that he has identified something objectionable. A gamer who "engages in the virtual act because $[. .$.$] the virtual act represents something that is$ taboo" (Young 2017a, p. 212) has to be aware that it would be morally wrong to enact those virtual acts in real life and that his real desire to act in such a way would be indicative of a real moral flaw in his character.

\footnotetext{
${ }^{3}$ It must be noted that the question about harmful or beneficial consequences of (violent) computer games on the player is an empirical one. It must therefore be investigated though empirical psychological studies. To date, there seem to be no studies that would prove the existence of substantially harmful consequences. See Ferguson (2010) and Reinecke \& Klein (2015).
} 
None of this, however, poses a substantial objection to the argument Ostritsch is making. Sure: If we classify $\mathrm{M}_{\text {(enjoyment) }}$ as a strong type of enjoyment, then $\mathrm{M}_{\text {(enjoyment) }}$ does contradict Ostritsch's claim that a player acts immorally when enjoying certain video games in a strong sense of "to enjoy". After all, the previous section highlighted good reasons for doubting that $\mathrm{M}_{\text {(enjoyment) }}$ is an objectionable way of playing computer games. However, if this is the case, then we should not classify $\mathbf{M}_{\text {(enjoyment) }}$ as a strong enjoyment in the sense intended by Ostritsch. After all, his distinction between two types of enjoyment must be seen in the context of his overall argument. And this argument is, as explained above, directed against the expressivist presupposition that "enjoying" fictional content of a morally questionable nature is necessarily expressive of a morally questionable character. All that the distinction between weak and strong enjoyment is supposed to show is that there is a sense of enjoyment (which Ostritsch calls "weak") that is not per se immoral. The question of how crude or refined the notion of strong enjoyment is does not even figure into this point. The crudeness of a notion is always relative to context and purpose. Therefore, it is not warranted to call the category of strong enjoyment "too crude": It is not too crude with respect to the sole purpose it serves in Ostritsch's argument, i. e. being the counterpart to "weak enjoyment" which in turn blocks the expressivist argument from going through. We thus object to Young's objection that the notion of strong enjoyment is too crude in the context of Ostritsch's argument against the expressivist.

On a charitable reading, the upshot of the distinction between strong and weak enjoyment is ultimately nothing else than a distinction between immoral and amoral ways of enjoying video games. On such a reading, "strong enjoyment" and "weak enjoyment" should be seen as the names for the immoral and the amoral type of enjoyment. Indeed, in Ostritsch's original paper, there is a lack of specification, for all we are offered is the very broad difference between 'having fun' and 'being interested'. Therefore, Young's clarification is quite enlightening. Yet, Ostritsch's original argument goes through anyway, because the decisive point about the distinction between weak and strong enjoyment is simply that there are some forms of enjoyment that are not morally reproachable. This point is made by Ostritsch to argue against the expressivist claim that playing a game of questionable content like RapeLay necessarily expresses a morally flawed character. All that the introduction of $\mathbf{M}_{\text {(enjoyment) }}$ adds is thus another example of a morally unquestionable type of enjoyment-a weak type if we follow Ostritsch's terminology, a strong type if we follow Young's wording. This, however, is a controversy about words and not about substance. With all this said, we can conclude that with $\mathrm{M}_{\text {(enjoyment) }}$ Young presents a most welcome refinement of the argument against the expressivist view, according to which the mere fact that someone is playing a game of questionable moral content allows us to make a moral judgment about the player's character.

(ii) Young's second concern with Ostritsch's characterization of strong enjoyment is that there is a motivationwhich Young calls $\mathbf{M}_{\text {(substitution) - which makes the playing }}$ of a game immoral, independently of any immoral content the game might endorse. $\mathbf{M}_{\text {(substitution) }}$ is defined by Young as follows:

$\mathrm{M}_{\text {(substitution) }}$ : $\mathrm{S}$ desires to engage in a particular realworld activity which happens to be taboo. This activity is represented by the virtual act. S therefore desires to engage in the virtual act (say, murder or rape or paedophilia) not because it is taboo (as is the case in $\mathrm{M}_{(\text {enjoyment) }}$ ) but because it represents the real-world activity $\mathrm{S}$ desires to engage in (which happens to be taboo). Enacting the real-world taboo affords $\mathrm{S}$ the opportunity to satisfy this desire, vicariously. (Young 2017a, p. 213)

Such a motivation is clearly wrong, at least from the point of view of virtue ethics, because a player with such a motivation is expressing (and perhaps even cultivating) ${ }^{4}$ a morally degenerate character trait. ${ }^{5}$ The case of $\mathbf{M}_{\text {(substitution) }}$ is, however, not a rebuttal of Ostritsch's argument. Rather, it is a welcome clarification of what could be regarded as one morally objectionable type of enjoyment. If someone plays a game - actually, any game-with the motivation of $\mathrm{M}_{\text {(substitution) }}$ and thereby satisfies morally questionable desires, he is morally at fault. This is not an objection to the argument Ostritsch is making with the help of the distinction between weak and strong enjoyment. ${ }^{6}$ Again: All

\footnotetext{
${ }^{4}$ As noted above in note 4, it is an empirical question whether there really are any such deteriorating (or ameliorating) effects of playing (violent) computers games on the player's character.

${ }^{5}$ Using a different ethical framework, however, it is an open question whether $\mathbf{M}_{\text {(substitution) }}$ necessarily is an immoral way of enjoying video games. A utilitarian e.g. would deem $\mathbf{M}_{\text {(substitution) }}$ morally laudable in case the fulfillment of immoral desires through video games results in the player not fulfilling them in reality. In other words: What if the player deliberately acts in certain ways in the virtual realm to prevent himself from acting accordingly in the real world? The act would contain an enjoyment as $\mathbf{M}_{\text {(substitution) }}$ without being clearly immoral. Using the terminology of Harry Frankfurt (1971), one might say that, in this example, the player reflects about his immoral first-order desires and decides to follow his morally laudable second-order desires, thereby preventing himself from real moral transgressions. Even from the point of view of Kantian ethics, such a Frankfurtian motivation seems anything but immoral. Therefore, $\mathrm{M}_{\text {(substitution) }}$ is not necessarily an example of an immoral way of engaging with video games - at least not independently of the question whether these games endorse actual immorality.

${ }^{6}$ Neither is it an objection to the endorsement view as such, but then again Young himself does not seem to attack the endorsement view itself but only the arguments for it. Cf. Young (2017a, p. 209, 218).
} 
that the distinction between weak and strong enjoyment is supposed to show is that there is no way to judge the moral character of the player based on the fact alone that he is playing a certain game. Because there are morally "innocent" types of enjoyment with which we can play a seemingly immoral game, i.e. types of enjoyment that are themselves not immoral (including Young's $\mathrm{M}_{\text {(enjoyment) }}$ ), there is no necessary or inherent connection between the character of the player and the fact that he is playing a video game of any kind (even including games like RapeLay). This is the reason why Young's alleged contradiction does not concern Ostritsch's argument: The latter does not limit the moral wrongness that might be involved in enjoying video games to only one specific way (the one depending on the game's endorsement of immorality).

In fact, Ostritsch can agree with Young's conclusion: " $\mathrm{M}_{\text {(substitution) }}$ exemplifies the expressivist's claim that someone who enjoys virtually enacting rape or paedophilia, or such like, is morally flawed" (Young 2017a, p. 213). This, however, does not contradict the argument that Ostritsch is making against the expressivist. All that Ostritsch wants to show-and Young's further distinctions of "to enjoy" actually support this-is that there is no way of taking the mere fact that someone is playing a certain game to be indicative of a certain kind of character. The reason for this is that playing a game can involve quite different types of enjoyment. Therefore, the case in which someone surprises a friend playing RapeLay and takes the act of playing as such to be proof of a morally degenerate character is not convincing. Before making such a judgment, we have to first establish why the friend played this game. ${ }^{7}$ This, however, is enough to show that there is no inherent connection between playing a seemingly immoral game and doing something immoral. Finding such an inherent connection however is exactly what the amoralist challenge is all about.

\section{Young's second objection: objective immorality}

Young's second objection is concerned with the question of how statements about the immorality of video games can be justified. Young criticizes Ostritsch for not offering a detailed account on how the moral quality of video games can be assessed without referring to either the developer's intentions or the player's reactions and interpretations (Ostritsch 2017, esp. p. 124 f.; see also Young 2017b). This, in itself, is not an objection to the endorsement view, since it does not point to any contradiction in the theory but only to a question the

\footnotetext{
${ }^{7}$ In her example, Patridge (2011, p. 305) offers some insight into the player's psyche who openly confesses that "I just had great time in there. You can even have sex with virtual children." It is this confession of the player's more than just weak enjoyment and not the mere act of playing that makes the expressivist argument compelling.
}

proponent of the endorsement view would have to elaborate on. Young, however, seems to believe that there is no objective answer to the question about the moral quality of a video game, and he believes so for meta-ethical reasons.

Young's meta-ethical argument starts with the observation that people may disagree about the morality or immorality of any given video game. As an example, Young refers to Ostritsch's claim that the video game Hatred (Destructive Creations 2015) is immoral because it glorifies actual murder:

[I]t is my contention that, as things stand, it is not in fact clear (or certainly not as clear as Ostritsch would have us believe) that Hatred is glorifying actual murder. So how can two opposing views be rationally held with equal conviction about the same content? (Young 2017a, p. 215)

Young seems to believe that only a position called constructive ecumenical expressivism (CEE) (Young 2017a, p. 215; see also Young 2014, 2015) can explain such disagreement in moral evaluation:

CEE postulates the following: where a shared moral attitude occurs with regard to some object or event (note that this shared moral attitude is different to a more general shared negative attitude [...]), even if different people have different reasons for this shared attitude, as a society we are able to create or construct a social norm that then acquires its own objectified moral standard [.] (Young 2017a, p. 215)

CEE is a clear-cut case of meta-ethical relativism. According to CEE, the truth of a moral judgment is relative to people's shared attitudes. Of course, CEE does not completely deny that moral judgements have some sort of objectivity to them. However, it is only by a social consensus, i.e. shared moral attitudes, that society creates social norms that become the valid "moral standard". According to CEE, moral objectivity is thus relative to a social consensus. And since such a consensus allegedly does not exist with regard to games like Hatred (Destructive Creations 2015) or even RapeLay (cf. Young 2017a, p. 216), these games cannot be called immoral.

We want to argue that Young's meta-ethical argument is flawed in two ways. The objections we offer are typically presented by moral objectivists or moral realists against antirealists. Of course, the debate between moral realism and anti-realism is much too vast in order to be settled here. Our two objections cannot establish the truth of moral realism. However, there is no need to establish the truth of moral realism either because our arguments do not presuppose it. As arguments against moral anti-realism (which includes the social constructivism of CEE) they stand on their own. In any case, we recognize both our affiliation with the objectivist or realist camp and the fact that there is a broader 
discussion about moral realism and anti-realism that is not settled by the following two objections.

First of all, Young believes that the moral relativism of CEE offers the best explanation of the fact that people disagree about a moral judgement. If a theory offers the best explanation of some phenomenon, we can also turn things around and say that the phenomenon in question supports the theory. However, there is reason to doubt that the fact of moral disagreement supports moral relativism (i.e. that moral relativism offers the best explanation for it). There is disagreement about everything, even about what the (nonmoral) facts of a given situation are. Are we therefore to believe that there are no objective facts independently of people's attitudes towards them? The answer is obviously "no". In the same vein then, we should not take moral disagreement to mean that there are no objective moral facts independently of the attitudes that people have towards them. One might even argue that the fact that people disagree and argue about the moral quality of an action or object points towards a presupposition among the disagreeing parties that that there is an objective truth of the matter. After all, the disagreement between the parties is about who gets things right. Of course, whether this presupposition of discourse is actually true, i.e. whether there really is such an objective fact of the matter, is a different question.

In any case, the mere fact of disagreement as such proves nothing regarding the discussed object. The discussion is to be settled through evidence and rational argument: If we believe Hatred to be immoral and Young believes it not to be immoral, we will simply have to engage in a rational debate about this very question. The way to settle such a moral debate about a computer game is nothing extraordinary. We will simply proceed in the same manner in which we are used to discuss the moral quality of other artworks, such as movies, dramas or paintings. Both parties will point to certain properties of the game in question, such as graphics, gameplay, narrative and - very important - those aspects of the game that belong to its "paratext" (see Genette 1997), like the title screen, loading screens, menus, end credits etc. (see Ostritsch 2018, 92 f.). The way to find out if Shakespeare's Merchant of Venice is really anti-Semitic or if Hatred really glorifies murder is not to look for what most people believe about these questions (as CEE would have us believe) but to take a close look at those works themselves. Without a doubt, ethical criticism of any artwork is not an easy task, simply because "good ethical criticism requires good literary criticism" (Devereaux 2004, p. 9). The same goes for the ethical criticism of computer games. Yet, this does not mean that it is not possible.

The second flaw in Young's argument is that CEE reduces normative and evaluative moral disputes to descriptive social disputes. Thus, CEE actually eliminates what it wants to explain, namely the moral disagreement about a game like Hatred. The fact that a certain number of people share a certain attitude or show a certain reaction towards a video game (or any other matter) can never be taken to be more than a symptom of its immorality. The decisive question is if those attitudes and reactions are warranted by the game itself. People that laugh at a tragedy do not thereby turn it into a comedy. Leaving aside extraordinary cultural or social settings that might warrant a modification or even reversal of reactions by the audience, comedic reactions to tragedy can be criticized as misplaced or inadequate at least partly because they seem to miss the dramatic qualities of the tragedy. All kinds of differences between aesthetics and morality notwithstanding, a similar relation holds between moral attitudes and emotional reactions on the one hand and video games on the other hand: The morality of a video game does not depend on people's reactions or interpretations. Instead, the moral qualities of the game are the standard by which people's reactions are to be judged as appropriate or inappropriate.

Yet, Young's reasoning contains a valuable hint for further studies: We should indeed somehow integrate the role of the player into an adequate analysis of video games. The reason for this, however, is not that the reactions and opinions of players shape the moral quality of the game, but that every player co-constitutes the game by playing it. This is the case because of a simple fact: A game without a player does not exist in its fully actualized form. Any actual game basically consists of actions - and actions can only be executed by a person: the player. Consequently, one has to acknowledge that video games are essentially co-constituted by the player's actions (Ostritsch/Steinbrenner 2018, pp. 64-68). Hence, for a proper analysis, one has to integrate the player as co-constituent of the video game and therefore: of its morality. In doing so, one has to acknowledge the special role of players which is different from the role of an actor or a performer in a play and also different from the role of an author of a script or a novel (Ostritsch 2017, p. 126 f.): When playing a game like Grand Theft Auto V (Rockstar North 2015), players neither merely act out a prewritten script for an audience nor do they create a fictional work from scratch. However, playing a game like Grand Theft Auto $V$ can (and typically will) involve playing that is somewhat similar to (improvised) acting, e. g. when the player pretends to be a character (Franklin, Michael, Trevor), but it can (and typically will) also involve playing that is not like acting at all, e.g. experimenting with the game mechanics. In any case, it is only through the actions of the player that the fictional world of the game, including its gameplay mechanics and its narrative, is actualized. Since "all play is a voluntary activity" (Huizinga 1980, p. 7), the player is somewhat responsible for the game he actualizes. The exact process of a game being co-constituted by the player's action 
and the extent of his moral responsibility in doing so would have to be the topic of a separate paper.

To sum up, the challenge of finding the right tools for an adequate moral evaluation of video games is not to be underestimated. And we acknowledge that it is beyond the limits of this paper to offer a comprehensive account of these tools. However, these considerations do not imply that the morality of a video game depends on the player's (or, more precisely, on a group of players') empirical reactions or interpretations as Young proposes. Likewise, a fairy tale's "moral" is not determined by the reader's opinion but by the piece of literature itself. It is only with reference to the work itself that we can distinguish adequate from inadequate ways of reading, understanding and interpreting it.

\section{Young's third objection: moral obligations}

In his third and final objection, Young criticizes Ostritsch's claim that gamers have moral obligations regarding games that endorse immorality. Young bases his criticism on the distinction between two types of actions that can be called wrong: On the one hand, there are actions that are morally forbidden. On the other hand, there are actions one merely ought not to carry out, so called suberogatory actions (Young 2017a, p. 217, see also Young 2017b). Young gives the following example for the latter:

[S] uppose a young and healthy man (S) and a heavily pregnant woman get on a bus at the same time, $\mathrm{S}$ just ahead of the woman. There is only one free seat and $\mathrm{S}$ takes it, knowing that the heavily pregnant woman will have to stand. Through his action, $\mathrm{S}$ has not violated a moral obligation-he has not done something forbidden-but he has, it seems reasonable to say, done something wrong. (Young 2017a, p. 217)

According to Young, the behavior of S may be called wrong, but it is not immoral. We disagree. None of the traditional ethics would judge the young and healthy man to be anything less than immoral. For the utilitarian, S acts immorally because the consequences of his actions do not maximize the happiness of the people involved. For the Kantian, S's blatant egoism cannot be squared with a maxime that would conform to the categorical imperative. For the Aristotelian, S's behavior exhibits a blameworthy disposition and a flawed character.

Leaving aside this one example, one might question whether suberogatory actions really exist. The most promising examples are of social or conventional nature, e.g. eating with your fingers (in some cultures) or speaking with your mouth full (in some cultures). Regarding such conventions, there are two possibilities with regard to their moral relevance-two possibilities that transform into a dilemma for Young's argument. Either one believes suberogatory actions to be utterly amoral (i.e. not of moral relevance at all), or one thinks that they are indeed morally relevant. There seem to be good reasons for both options. Clearly, someone who knowingly and willingly disregards social norms without any higher aesthetic or moral reason for doing so may be called anti-social, repugnant, disruptive etc. These attributes, however, could be seen as immoral qualities. If that is the case, it makes it doubtful whether suberogatory actions really exist and Young's argument loses its basis. If one, however, choses (like Young does) the first option, according to which social conventions in general and suberogatory actions in particular are not morally relevant, then one has-by definition-left the realm of morality. In that case, one has entered the realm of good or poor taste which may or may not be successfully analyzed by CEE (cf. Young 2017b). However, if the discussion is about the immorality of games-and this is precisely what the endorsement view is interested in-then the conformity or non-conformity to merely conventional taste is irrelevant. After all, if poor or good taste is a matter of descriptive social convention and not a matter of normative morality, then taste is irrelevant to the question of the morality or immorality of computer games. Therefore, Young's third objection is not an objection to the endorsement view at all. Rather, it marks a shift to a different discussion, away from normative ethics and towards the descriptive sociology of taste.

A proponent of Young's position might reply that the change from morality/immorality to good/poor taste is not intended as a move from the normative to the descriptive. Instead, the Youngian could point out that the distinction between good and poor taste is itself supposed to be normative. Young actually argues in another paper that criticizing an action $x$ as an expression of poor taste means that " $x$ ought not to be done" with "ought" here being used in the sense of the "suberogatory" (Young 2019, p. 466, 468). According to Young, what is expressed by this "ought" is a "negative attitude" of the speaker "towards the treatment of something one (one's society) already considers to be immoral" (e.g. a certain fictional treatment of the topic of murder or rape) (Young 2019, p. 481). However, as Young explains, this negative attitude itself has not (yet) been solidified into a moral norm by a social consensus (cf. Young 2019, p. 481). We have argued above against the idea of arriving at morality through social consensus. But even if we accept CEE for argument's sake, the "ought (not)" in statements of good/ bad taste cannot—at least not in itself-have any normative force on someone who simply does not share the attitude of the person who makes the judgment. If a person's judgement about something being in bad taste is merely an expression of his negative attitude towards the "perceived treatment" (Young 2019, p. 481) of a morally pertinent matter, it does not follow that another person should share that perception, let at alone that he should share that attitude. After 
all, according to Young, judgments about poor taste differ from judgement about immorality precisely with regard to this lack of social consensus. Therefore it seems that if one ventures into the realm of good/bad taste to explain suberogatory actions, one must also leave the normative realm of ethics and enter the field of descriptive sociology.

Acknowledgement We are thankful for the valuable comments and criticism offered by the two anonymous referees.

Funding Open Access funding provided by Projekt DEAL. Deutsche Forschungsgemeinschaft (DE) (Project number: 413050359).

Open Access This article is licensed under a Creative Commons Attribution 4.0 International License, which permits use, sharing, adaptation, distribution and reproduction in any medium or format, as long as you give appropriate credit to the original author(s) and the source, provide a link to the Creative Commons licence, and indicate if changes were made. The images or other third party material in this article are included in the article's Creative Commons licence, unless indicated otherwise in a credit line to the material. If material is not included in the article's Creative Commons licence and your intended use is not permitted by statutory regulation or exceeds the permitted use, you will need to obtain permission directly from the copyright holder. To view a copy of this licence, visit http://creativecommons.org/licenses/by/4.0/.

\section{References}

Destructive Creations. (2015). Hatred. Gliwice: Destructive Creations.

Devereaux, M. (2004). Moral judgement and works of art: The case of narrative literature. The Journal of Aesthetics and Art Criticism, 62(1), 3-11.

Ferguson, C. J. (2010). Blazing angels or resident evil? Can violent video games be a force for good? Review of General Psychology, 14(2), 66-81.

Frankfurt, H. (1971). Freedom of the will and the concept of a person. Journal of Philosophy, 68(1), 5-20.

Genette, G. (1997). Paratexts: Thresholds of interpretation. Cambridge: Cambridge University Press.
Huizinga, J. (1980). Homo Ludens. A study of the play-element in culture. London: Routledge \& Kegan Paul.

Illusion. (2006). RapeLay. Yokohama: Illusion.

Ostritsch, S. (2017). The amoralist challenge to gaming and the gamer's moral obligation. Ethics and Information Technology, 19(2), 117-128.

Ostritsch, S. (2018). Ethik. In D. M. Feige, S. Ostritsch, \& M. Rautzenberg (Eds.), Philosophie des Computerspiels. Theorie-PraxisÄsthetik (pp. 77-96). Stuttgart: Metzler.

Ostritsch, S., \& Steinbrenner, J. (2018). Ontologie. In D. M. Feige, S. Ostritsch, \& M. Rautzenberg (Eds.), Philosophie des Computerspiels. Theorie-Praxis- Ästhetik (pp. 55-74). Stuttgart: Metzler.

Patridge, S. (2011). The incorrigible social meaning of video game imagery. Ethics and Information Technology, 13(4), 303-312.

Reinecke, L., \& Klein, S. A. (2015). Game Studies und Medienpsychologie. In K. Sachs-Hombach \& J.-N. Thon (Eds.), Games Studies. Aktuelle Ansätze der Computerspielforschung (pp. 210-251). Köln: Herbert von Halem.

Rockstar North. (2015). Grand Theft Auto V. New York: Rockstar Games.

Young, G. (2014). A meta-ethical approach to single-player gamespace: Introducing constructive ecumenical expressivism as a means of explaining why moral consensus is not forthcoming. Ethics and Information Technology, 16(2), 91-102.

Young, G. (2015). Violent video games and morality: A meta-ethical approach. Ethics and Information Technology, 17(4), 311-321.

Young, G. (2017a). Objections to Ostritsch's argument in "The amoralist challenge to gaming and the gamer's moral obligation". Ethics and Information Technology, 19(3), 209-219.

Young, G. (2017b). Integrating poor taste into the ongoing debate on the morality of violent video games. The Computer Games Journal, 6(4), 227-237.

Young, G. (2019). An expressivist account of the difference between poor taste and immorality. Ethical Theory and Moral Practice, $22,465-482$.

Publisher's Note Springer Nature remains neutral with regard to jurisdictional claims in published maps and institutional affiliations. 